\title{
EMENTA: \\ "Tribunal de Justiça - Quinto Constitucional - Composição - Acesso dos Juízes Classistas do Tribunal de Alçada ao Tribunal de Justiça"
}

\author{
Dr. Carlos Thompson Flores
}

Ministro aposentado e ex-Presidente do Supremo Tribunal Federal

Obs.: O presente parecer foi acolhido pelo Plenário do TJ/RS, em aresto que se encontra publicado na RJTJRGS, 110/209.

\section{PA R E C E R}

Para o devido exame das questões de direito suscitadas na consulta, impõe-se, primeiramente, a segura reconstituição dos fatos, para, após, em busca da correta solução, verificar as normas jurídicas que sobre eles incidem.

Faço-o à vista das xerocópias extraídas dos autos e de documentos outros a eles relacionados.

\section{I - OS FATOS}

Assim os descreve a petição inicial da ação de mandado de segurança ajuizada perante o Egrégio Tribunal de Justiça, em 30 de setembro último, pela Ordem dos Advogados do Brasil, Secção do Rio Grande do Sul, por seu Presidente:
“Aposentando-se, a pedido, o Desembargador Werter R. Faria (cfe. ato publicado no Diário Oficial de 05 de setembro/83, p. 12), que ingressara no Tribunal de Justiça em lugar do quinto reservado a advogado, reuniuse o colendo Tribunal Pleno, em Órgão Especial, no dia 26-9-83, para, entre outros assuntos, dar cumprimento ao que prescreve o artigo 13, VI, do Código de Organização Judiciária do Estado.

Elaborada a lista, nela foram incluídos os Doutores Ernani Graeff, José Maria Rosa Tesheiner e Luiz Fernando Borges da Fonseca, todos inclitos e honrados juízes do Tribunal de Alçada do Estado. Embora para lá tenham sido conduzidos na condição de advogados, tais indicaçôes, atualmente, profligaram direito líquido 
e certo de todos os advogados no efetivo exercício da profissão, eis que para preencher lugar a estes reservado, no Tribunal de Justiça, as escolhas recaíram em nomes de magistrados. Esses nomes, e tão somente esses, serão submetidos ao Governador do Estado, que condicionado restará a nomear um deles para o cargo de Desembargador do Tribunal de Justiça do Estado.

Com efeito. Entende a impetrante que, assim deliberando, o Colendo Tribunal Pleno, em Órgão Especial, ofendeu direito individual de cada um dos integrantes da classe. cujos interesses gerais representa por força da Lei $n^{\circ} 4.215$, de 27 de abril de 1963. E ofendeu por contrariar o que dispõe o artigo 100 da Lei Complementar $n^{\circ} 35$, de 14 de março de 1979, combinado com o artigo 144, IV, da Constituição Federal, e mais os artigos 46, $\S 1^{\circ}$, do Código de Organização Judiciária do Estado (Le Estadual $n^{\circ} 7.356$, de $\left.1^{\circ}-02-80\right)$ e 130 , $\S 2^{\circ}$, da Carta estadual."

\section{II - O DIREITO}

\section{A) DOPROCEDIMENTOJUDICIAL}

1. Cuidou o pedido, inicialmente, de justificar a cabência da pretensão, afirmando, verbis:

"Excluída a classe dos advogados da lista composta perpetrada está a lesão do direito subjetivo de todos os advogados no exercício efetivo da profissão, de nela se verem nominados, a si ou a seus pares."

$\mathrm{E}$, argumentando que a nomeação decorre de ato complexo, do qual participam os
Poderes Judiciário e Executivo, dispensável se tornava, para a invocação da lesão, que ela, a nomeação, se verificasse, eis que já se consumara, com a própria fatura da lista, à qual teria de se ater o Executivo, para o efeito da escolha.

2. Sustentou a inicial, após, a legitimidade ativa da Ordem dos Advogados, invocando em seu prol a Lei ${ }^{\circ} 4.215$, de 27-41963 - art. $1^{\circ}$, parágrafo único, e art. 20.

Dizem eles, respectivamente:

“Art. $1^{\circ}$. (...)

Parágrafo único. Cabe à Ordem representar, em juizo e fora dele, os interesses gerais da classe dos advogados e os individuais relacionados com o exercício da profissão.

Art. 20. À Secção incumbe exercer, no território respectivo, as funções e atribuições da Ordem dos Advogados do Brasil."

3. No pertinente ao mérito, longamente sustentou sua procedência. Operou, especialmente com o art. 144, IV, da Constituição Federal, e art. 100, da Lei Complementar $\mathrm{n}^{\circ} 35$, de 14-3-1979.

Dizem ditos preceitos, respectivamente: “Art. 144. (...)

IV - na composição de qualquer Tribunal um quinto dos lugares será preenchido por advogados, em efetivo exercício da profissão, e membros do Ministério Público, todos de notório merecimento e idoneidade moral, com dez anos, pelo menos, de prática forense. Os lugares reservados a membros do Ministério Público ou advogados, serão preenchidos, respectivamente, por membros do
Ministério Público ou advogados, indicados em lista tríplice;

Art. 100. Na composição de qualquer Tribunal, um quinto dos lugares será preenchido por advogados, em efetivo exercício da profissão, e membros do Ministério Público, todos de notório merecimento e idoneidade moral, com dez anos, pelo menos, de prática forense."

Invocou, por último, tanto no que concerne às prejudiciais, quanto ao merecimento, opinião de autores, e julgados, estes do Egrégio Supremo Tribunal Federal, com indicações que precisa. liminares.

Postulou, outrossim, concessão de

4. Distribuído o feito, indeferiu-as seu eminente Relator, solicitando informações, e determinando a citação dos litisconsortes necessários, os juízes cujos nomes integraram a lista tríplice acoimada de ilegal.

5. Em longo e fundamentado ofício, prestou o eminente Presidente do Tribunal de Justiça as informações solicitadas pelo nobre Relator. Invocando tratadistas e comentando julgados do Supremo Tribunal, conclui que o ato impugnado não padece do vício apontado pela impetrante.

6. Em 26 de outubro último, pediram intervenção na causa 22 juízes do Tribunal de Alçada, todos oriundos da magistratura. Fizeram-no como terceiros interessados, fundados no art. 50 do C.P.C., e com o propósito de verem mantido o ato impugnado.

Como as informações, negam eles a existência de qualquer vício que pudesse tornar ilegal o ato em questão. Trazem, em abono de sua larga fundamentação, opiniões de juristas e julgados do Supremo Tribunal Federal, dos quais destacam fragmentos de votos, sobre os quais tecem comentários. Terminam postulando seja indeferido o mandamus.

7. A essa altura processual, é que ditos assistentes formulam a presente consulta.

\section{B) DODESLINDE DA CONTROVÉRSIA}

\section{1 - Das prejudiciais}

1.1 - Posto que o ato administrativo emane do Órgão Especial do Tribunal de Justiça, que faz as vezes de seu Plenário, nos termos do inc. V do art. 144 da Constituição, cabe a ele a competência originária para julgar o mandado de segurança presente, segundo jurisprudência do Supremo Tribunal Federal, extratificada em sua Súmula 330, e aplicação posterior (MS 20.051-MG, Rel. Min. Bilac Pinto, Pleno, 22-476; MS 19.994-PR, Rel. Min. Rodrigues Alckmin, Pleno, 14-8-74, in RTJ, 70/645-6).

1.2 - No que tange à legitimidade ativa da Ordem dos Advogados para a impetração da segurança, tenho que as disposições específicas de seu Estatuto — Lei no $4.215 / 63$ - antes transcritas, arrebatam qualquer dúvida a respeito, conferindo-lhe absoluta legitimatio ad causam. Neste sentido, ademais, é a jurisprudência do Supremo (RTJ, 89/396-418; RDA, 144/78-85)

1.3 - Por último, no que respeita às prejudiciais, considero cabível, em tese, o procedimento judicial do qual se serviu a requerente.

Ainda que a nomeação de desembargador, integrante do quinto, deflua de ato complexo, não se faz mister sua finalização para o uso da medida judicial. É bastante que, qualquer de seus componentes, importe, por si, em lesão. E, no caso, a ilegalidade assentaria na elaboração da lista integrada por juízes, e não 
por advogados, em efetivo exercício da profissão, lista essa a qual se teria de ater o Governador para o efeito da escolha e nomeação. Arrima-se, assim, o remédio usado no art. $1^{\circ} \mathrm{da}$ Lei $n^{\circ} 1.533 / 1951$, com o sentido e alcance que se lhe tem atribuído.

1.4 - Acrescente-se, a derradeiro, que legítima é a intervenção dos juízes oriundos da carreira. Seu interesse é manifesto para que prevaleça o ato impugnado, pois, do contrário, iriam os integrantes da lista, que não se originaram, como eles, da carreira, prejudicá-los no acesso ao Tribunal de Justiça, fim a que todos almejam. Ampara-se, pois, seu pedido, no art. 19 da citada Lei ${ }^{\circ} 1.533$, combinado com o art. 50 do C.P.C.

\section{2 - Do mérito}

2.1 - O longo e bem deduzido pedido formulado pela impetrante assenta, por inteiro em dois dispositivos: o art. 144, IV, da Constituição e o art. 100, caput, da Le Complementar nº 35, de 1979 (Lei Orgânica da Magistratura Nacional), ambos anteriormente transcritos.

Operando com eles, e com o julgado proferido pelo Egrégio Supremo Tribuna Federal, na Representação $\mathrm{n}^{\circ} 1.006-\mathrm{RJ}$, tomado por maioria de votos (RTJ 92/460-84), considera que a lista tríplice, elaborada pelo Cdo. Tribunal de Justiça, por seu Órgão Especial, para o provimento de vaga na Corte em questão, reservada aos advogados, em efetivo exercício da profissão, por conter, apenas, nomes de juízes, posto que oriundos da mesma classe violou direito líquido e certo, assegurado po aqueles preceitos, não podendo, conseqüentemente, prevalecer.

2.2 - Penso, data venia, não assistir razão à requerente como o demonstraram as informações prestadas pelo nobre Presidente do Tribunal de Justiça, robustecidas pelos fundamentos aduzidos pelos assistentes, através da petição que formularam seus ilustres patronos.

2.3 - O relevante tema constitucional, como é sabido, não se oferece novo, e foi, exaustivamente, examinado pela Suprema Corte, nos julgamentos das Representações $n^{\circ}$ s 879RS e 881-MG, das quais foram relatores, respectivamente, os eminentes Ministros Antonio Neder e Djaci Falcão, publicadas na RTJ, 67/630-46 e 66/631-58.

Para o julgamento de ambas concorri com o meu voto. Pela relevância da questão constitucional então debatida - composição dos Tribunais - fora de meus hábitos, amante da concisão, longamente fundamentei minha convicção. Mantive-me fiel a esses votos, posteriormente, no julgamento da referida Representação $n^{\circ} 1.006$, da qual foi relator o eminente Ministro Leitão de Abreu. Formei, então, com os nobres Ministros Soares Muñoz, Djaci Falcão e Antonio Neder, a corrente que se tornou vencida.

Hoje, passados mais de quatro anos, meu convencimento persevera, talvez mais robustecido, data venia, através de novas leituras e mais serena meditação.

\section{4 - Realmente}

No julgamento, em conjunto, das Representações $n^{\circ} \mathrm{s}$ 879-RS e 881-MG, em sessão de 13-12-1972, há um voto que classifiquei, então, de depoimento histórico, sem prejuízo de seu alto valor jurídico que lhe atribuí, o qual jamais poderia olvidar. Refiro-me àquele que proferiu, naquela memorável sessão, o eminente e saudoso Ministro Rodrigues Alckmin

S. Exa., com a clareza e precisão que lhe eram peculiares, mostrou as três soluções que se apresentaram ao Tribunal de Justiça, no longínquo ano de 1950, para conceituação do Tribunal de Alçada, o qual a Constituição de 1946 instituíra por proposta do então
Desembargador Mário Guimarães, seu Presidente.

Limitara-se aquele Estatuto a dispor, em seu art. 124, II, verbis:

"Poderão ser criados tribunais de alçada inferior à dos Tribunais de Justiça" (Rev. For., 108/192)

Antes de mais nada, carecia-se de Lei Estadual, provendo sobre criação do Tribunal.

Autorizado pelo T.J., encarregou-se do anteprojeto o saudoso Desembargador Percival de Oliveira. Aprovado pela Corte, e encaminhado à Assembléia Legislativa, originou a Lei $\mathrm{n}^{\circ} 1.162$, de 31 de julho de 1951 (José Frederico Marques - A Reforma do Poder Judiciário, $1979,1^{\circ}$ vol. p. 387, notas 3 e 4).

Impendia, além de providências outras, cuidar de sua composição originária e das condições de acesso de seus componentes ao Tribunal de Justiça.

E, justificadamente, o douto Ministro, analisou as três soluções apresentadas e a opção por aquela que veio a ser acolhida, a qual, decorridos, então, vinte e um anos de constante aplicação, produziram os melhores resultados, agradando, ademais, a gregos e troianos, juízes de carreira, advogados e membros do Ministério Público (RTJ, 66/647-9).

Essa foi, também, a orientação tomada pelo Eg. Tribunal de Justiça do Rio Grande do Sul, não só no caso objeto da Representação, antes citada, como na que veio a originar o ato, impugnado no mandado de segurança em comentário, e a cuja orientação aderiu a totalidade dos juízes de carreira do Tribunal de Alçada, ora assistentes do procedimento judicial em questão.

2.4.1 - Considero, como aqui reproduzidos os fundamentos que constam naqueles decisórios, aos quais me reportei, ao votar no julgamento da Representação no 1.006 -
RJ, em sessão plenária de 10-5-1979 (RTJ, 92 483-4).

Permito-me transcrever, em parte, a ementa da primeira delas - Representação $n^{\circ} 879$ $\mathrm{RS}$, verbis:

“... Os juizes que, no Tribunal de Alçada, integram o quinto que a $C . F$ reserva a advogados ou membros do M.P., poderão concorrer, a critério do Tribunal de Justiça, ao preenchimento de vaga da mesma natureza que se verifique nesse último Tribunal" (RTJ, 67/630)."

2.4.2 - De fato, os advogados como os membros do Ministério Público que ingressam nos Tribunais de Alçada, para comporem o quinto que lhes é reservado, na totalidade de seus juízes, embora desfrutando, desde a posse, das garantias atribuídas aos magistrados, jamais, em tempo algum, se desvinculam, por inteiro, da classe profissional de onde provieram. E isto, pela razão mesma que justifica sua presença nas Cortes em questão.

Tanto é certa essa afirmação que, ao vagarem suas cátedras, por qualquer motivo, são elas preenchidas por profissionais da mesma procedência. Nem poderia ser tal provimento procedido através de critério outro, pois que, se assim ocorresse, teriam eles que competir com os juízes profissionais, os quais integram a carreira de magistrados, da qual são aqueles, os classistas, inteiramente estranhos, como os conceitua Pontes de Miranda (Coments. à Constituição de 1934, II, p. 18; Coments. à Constituição de 1967, Emenda 1/69, IV, p. 320).

Admitir tal competição, como, implicitamente, sustenta a requerente do mandamus, importaria em dupla contrariedade à Constituição.

De um lado, afetaria a carreira dos magistrados, uma de suas proeminentes garantias, disciplinada que é, de forma rígida e 
exaustiva, na Constituição - art. 144, I, II e III com o ingresso de profissionais a ela estranhos sem satisfazerem as exigências para nela se integrarem.

A propósito, e versando sobre funcionários públicos comuns, preleciona Hely Lopes Meireles, em seu Direito Administrativo Brasileiro, 7.ed., 1979, p. 390:

"Cargo de carreira é o que se escalona em classes, para acesso privativo de seus titulares, até o da mais alta hierarquia profissional" (Os últimos grifos são nossos).

De outra parte, a adoção do critério propugnado pela impetrante viria fraudar a própria composição do Tribunal de Justiça: dilataria o quinto reservado aos classistas, 0 qual não seria mais um quinto, reduzindo, em prejuízo dos juízes da magistratura de carreira como a Constituição os qualifica (art. 144, I - o ingresso na magistratura de carreira...), a cota dos quatro quintos que lhes é privativa, e cuja integração a eles cabe, pelas duas únicas vias de acesso: antigüidade de classe e merecimento, como manda, ainda, a Constituição (art. 144, III).

Com clareza, preleciona Castro Nunes (Teoria e Prática do Poder Judiciário, p. 489):

“...Os dois critérios estão no preceito constitucional indicados paritariamente, “ (...) mediante promoção por antigüidade e por merecimento", não podendo o legislador local adotar fórmula que importe sua fraudação."

Esãode Mário Guimarães estas expressivas palavras (O Juize a Função Jurisdicional, p. 120):

"A Constituição prescreveu os dois meios únicos pelos quais pode ser conseguida a promoção: antigüidade ou merecimento. Não é lícito ao Estados, nem mesmo às leis federai criar um terceiro" (o grifo é nosso).
Afirmando os mesmos princípios, decidiu o Supremo Tribunal Federal, ao julgar, em sessão plenária, em 04-01-1956, o R.M.S. n 3.075-MG, do qual foi relator o eminente Min. Nelson Hungria (Rev. For., 167/136-9)

2.4.3 - Nem se pretenda considerar que ditos juízes classistas se incorporem à carreira, como forma única de não se quedarem no cargo em que foram investidos.

Quando a Constituição aceita a integração na carreira, em grau qualificado, por terceiro a ela estranho, por se tratar de exceção, ela o faz expressamente.

É o que se lê, no pertinente ao magistério, de grau médio e superior, por seu art. 176, $\S 3$, VI.

Com respeito à magistratura de carreira nem no acesso aos tribunais, ela, a Constituição, concede este desvio, porque, se o quisesse fazer, o teria expressado, o que não sucedeu.

Demais, o mal do estacionamento dos juízes classistas no Tribunal de Alçada pode inexistir, pois admite-se tenham ingresso no Tribunal Superior, porém para a mesma classe de onde se originaram.

A oportunidade, dirá o Tribunal de Justiça, e dependerá, como é óbvio, das qualidades que revelarem ditos Juízes no desempenho de sua atividade funcional.

Não se trata, evidentemente, de promocão, em seu sentido próprio, o que importaria no reconhecimento de um direito que é imanente à carreira

Antes, cuida-se de mera expectativa, cuja concretização, como se afirmou atrás, irá depender dos próprios juízes classistas, no desempenho de sua atividade com a origem profissional, segundo o critério que, nessa apreciação, venha a fazer o Tribunal Superior, quando se tratar de vaga nele ocorrida, e na mesma classe.
Certo não usará o Tribunal em questão do mesmo critério adotado para apreciar merecimento dos juízes da carreira, mas do juízo que venha a formar, no que concerne a eles, dos predicamentos que conservam de sua origem profissional, os quais é que conduzirão seus julgamentos na apreciação das questões que lhes forem afetas, no considerarem os fatos, e na adoção dos princípios jurídicos que sobre eles venham a incidir.

A propósito, relembrei, nos votos que proferi nas Representações 879 e 881 , com guardavam os Desembargadores classistas do Tribunal de Justiça deste Estado, a marca de sua procedência profissional, a qual era a razão mesma de sua especial participação nos julgamentos da Corte

Com propriedade, salientou, então, eminente Ministro Eloy da Rocha:

"O ilustre Procurador do Tribunal de Justiça do Rio Grande do Sul (tratava-se do Prof. Paulo Brossard de Souza Pinto), na Rp. 879, fez interessante observação sobre a experiência do advogado, que o juiz não perde, porque, si a perdesse, no convívio com outros juizes, as qualidades que o indicaram para $o$ Tribunal, não haveria mais razão para sua permanência no Tribunal" (RTJ, 67/645).

Outrossim, a origem dos juízes em questão é a eles inerente e de forma indissociável, desde o seu ingresso nos Colegiados, até ultimarem sua judicatura. Jamais poderão eles, por qualquer maneira, transpor os lugares que lhes foram reservados, em percentagem certa, para ocuparem os dos outros, os da carreira, e cuja fração determinada, também, não pode ser alterada.

Este foi, ademais, o entendimento constante que a tais juízes deram os tribunais, desde 1934, quando a Constituição tornou obrigatória sua integração nas Cortes locais, como o informam Mário Guimarães e Castro Nunes (ob. cit. p. 100-1 e 501-2, respectivamente), merecendo, tal entendimento, integral apoio do Supremo, como se verifica no julgamento do $M S n^{\circ} 1.0600-E S$, do qual foi relator o eminente e saudoso Min. José Linhares (Plenário de 25 10-1950, in RDA, 31/310-12).

2.4.4 - Acrescente-se que a Lei Complementar $\mathrm{n}^{\circ} 35 / 79$, em seu art. 111, segue 0 mesmo princípio, ao dispor:

"Nos Estados com mais de um Tribunal de Alçada é assegurado ao seus juizes o direito de remoção de um para outro Tribunal, mediante prévia aprovação do Tribunal de Justiça, observado o quinto constitucional".

Fundado em igual inspiração, assim já dispunha a L.O.J. do Estado do R.J., proibindo a remoção dos juízes do quinto do T. de Alçada para as Varas da última entrância, as quais, para o efeito da carreira, se equiparava o citado Tribunal.

2.5 - Emprestou a requerente, em seu petitório, especial relevo às expressões das quais se servem os arts. 144, IV, e $100 \mathrm{da} \mathrm{Lei}$ Complementar $n^{\circ} 35 / 79$, ou seja, estarem os advogados em efetivo exercício da profissão, ao ser elaborada a lista para provimento de vaga atribuída à sua classe, o que não teria ocorrido com respeito à relação impugnada.

E, em sua ajuda, invoca, como já se aludiu, o julgado proferido na Representação $\mathrm{n}^{\circ} 1.006-\mathrm{RJ}$, quando, ao citado fundamento, foi acrescido destaque à paridade integral, para todos os efeitos, entre juízes do Tribunal de Alçada, independentemente de sua origem profissional.

2.5.1 - Tais fundamentos ficaram respondidos nos votos que integram a expressiva maioria, nas Representações, também já comentadas, $n^{\circ}$ s. 879 e 881 . 
Permito-me destacar, porque de alta significação, este fragmento do voto do saudoso Ministro Rodrigues Alckmin (RTJ, 67/ 648-9):

“... Entendeu-se, portanto afastando uma literalidade $d$ interpretação que nada recomendava que o efetivo exercício da profissão havia de ser considerado quando advogado ou membro do Ministério Público fosse convidado a ingressar no Tribunal. Preenchido esse requisito, poderia ele, posteriormente, ter acesso dentro de sua classe a um cargo na classe idêntica do Tribunal de Justiça Esta experiência ou esta orientação, esta construção, através das omissões $e$ dos desencontros dos texto constitucionais, pareceu feliz, porque afastou todos aqueles embaraços que outra orientação traria à organização judiciária dos Estados, e tem, há vinte um anos, dado bons resultados, sem maiores problemas, na organização judiciária do Estado de São Paulo. Tenho, portanto, que a adoção desse critério, que não se prende à só literalidade de um pequeno texto constitucional mas que encara construtivamente, todos os texto referentes à organização judiciária dos Estados (o estabelecimento da carreira de juiz, o ingresso na carreira, a promoção de entrância a entrância até a última entrância em que se fará a escolha para o Tribunal) tenho que essa interpretação, que se afina a todos os textos da Constituição sem prender-se tão só à literalidade de uma pequena expressão, deve ser aceita".

Tudo conspira, pois, para que a interpretação literal das expressões comentadas ceda à exegese teleológica, sempre predominante na aplicação dos textos constitucionais, na lição dos mestres, bem recolhida por Maximiliano (Hermenêutica e Aplicação do Direito, 9. ed., 1979, p. 314, nº 378)

É ela que proporciona a vivificação dos textos vistos, em conjunto, como integradores de um sistema, sem o qual não teriam o sentido que se lhes quis atribuir: proporcionar o acesso dos classistas dos Tribunais de Alçada ao Tribunal de Justiça, na classe correspondente sem afetar a carreira dos magistrados profissionais.

Importaria a adoção deste critério no benefício de todos.

Dos classistas propriamente ditos, procurando pelo estudo e dedicação às causas que tiverem de examinar, o estímulo para verem reconhecidos seus méritos e assim compensados com o acesso ao Tribunal Superior.

Dos magistrados de carreira, porque não sofreriam competição com aqueles para o efeito das promoções, tornando assim mais atraente $\mathrm{e}$ sedutor o caminho que abraçaram.

Dos jurisdicionados, porque alcançariam julgamentos proferidos por juízes alimentados pela chama de bem servir, em troca do reconhecimento de seus méritos para um acesso sempre almejado.

2.5.2 - De outra parte, não vejo em que a Lei Complementar $n^{\circ} 35$, de 1979 , tenha contribuído para a alteração do entendimento consagrado nos julgamentos das primeiras representações.

Invoca a requerente do mandamus $o$ art. 100 , caput. No que pudesse interessar, é repetição das expressões do art. 144, IV, da Constituição, e já ficou respondido.

Acrescento, seu $\S 4^{\circ}$, aludido na Representação $\mathrm{n}^{\circ} 1.006$.

Dizele:
“Art. 100. (...)

$\S 4^{\circ}$. Os juizes que integram os Tribunais de Alçada somente concorrerão às vagas do Tribunal de Justiça correspondentes à classe dos magistrados".

Ao votar naquela Representação, como afirmei, não se fazia mister seu exame, eis que não estava ele em vigor. Deixei para, em oportunidade outra, quando estivesse em vigência. Não ocorreu. Nem me consta que tenha sido enfrentado até hoje pela Suprema Corte.

De qualquer forma, como afirmei atrás, meu convencimento não se alterou. Leio o preceito, menos preso às suas palavras do que a seu sentido. Compreendo-o, conjugado ao já citado art. 111, que bem evidencia a distinção dos juízes, segundo a sua origem, mesmo que integrem o mesmo Tribunal, o que se me afigura lógico e jurídico. Se não aceita o citado art. 111 a remocãa ou permuta de juízes de segundo grau, de classes de origens diversas, porque os reconhece segundo a proveniência e para que se mantenha o equilíbrio na composição: um quinto dos juízes classistas e quatro quintos dos de carreira, como iria confundi-los e nivelálos na promoção para a qual a remoção é um minus?

O nivelamento, pois, ou a equiparação de todos os juízes do Alçada para o efeito de promoção, por merecimento e antigüidade, não poderia, racionalmente, defluir do parágrafo em comentário, apesar de reconhecer sua ambígua e defeituosa redação. Conflitaria com a carreira instituída como relevante garantia dos magistrados que nela ingressaram, no degrau primeiro, e afetaria a própria cota de composição do Tribunal Superior, princípios que a Constituição instituiu, os quais não podem ser por qualquer forma contrariados, como antes já se havia considerado.
O que ali, no parágrafo, se quis afirmar foi a possibilidade do acesso dos classistas, dentro da sua respectiva classe, reforçando a tese que é para seu ingresso no Tribunal que se exige o exercício efetivo; e que, se o fizerem no ingresso ao Alçada, tal condição já se cumpriu, podendo ensejar seu aproveitamento no Tribunal de Justiça, obviamente, na mesma classe.

É provável mesmo que, para dirimir dúvidas a respeito do aproveitamento dos classistas do Tribunal de Alçada, prevenindo o justo temor de cristalizarem na Corte, tenha advindo o citado $\S 4^{\circ}$ do art. 100 , o qual não integrava o Anteprojeto da Lei Orgânica da Magistratura Nacional.

Tal dúvida originou, no Estado de São Paulo, onde se iniciou a criação dessa Corte, a dificuldade em se prover as vagas reservadas para o quinto, o que importaria na dificuldade na seleção dos maiores valores da respectiva classe, como bem analisa e ilustra o saudoso Ministro Barros Monteiro, com exemplos concretos ocorridos naquele Estado (RTJ, 66/ 644-5).

2.6 - Ante tão longas e, por vezes, repetidas considerações, resta apenas responder às questões propostas pelos consulentes.

É o que se passa a fazer, em seguimento.

\section{III - RESPOSTAS CONCLUSIVAS \\ ÀS DÚVIDAS SUSCITADAS}

Quanto à $1^{\mathbf{a}}$, NÃO. Improcedem, inteiramente, todas as prejudiciais, incompetência do T.J., ilegitimidade ativa da requerente, incabência do mandamus de que se serviu, bem como falta de interesse dos consulentes para intervirem como assistentes, na defesa do ato impugnado. 
Quanto à $2^{\mathrm{a}}$, NÃO. Considero que a Lei Complementar $\mathrm{n}^{\circ} 35$, de 1979 , no que respeita ao ingresso dos advogados e membros do Ministério Público, nos Tribunais, não alterou o critério para sua escolha, bastando se busque harmonizar suas disposições com as correspondentes da Constituição, às quais se devem submeter.

Quanto à $3^{\mathrm{a}}$, SIM. Penso que deve prevalecer, no pertinente, a interpretação do citado art. 144 e seus incisos, da Constituição, a exegese que lhes atribui o S.T.F., nas comentadas Representações $n^{\circ}$ s 879 e 881 , inobstante o que decidiu a mesma Corte, na Representação $\mathrm{n}^{\circ} 1.006$, contra quatro votos, não sendo de meu conhecimento que tal orientação tenha sido reiterada, em julgamento posterior e nova composição da Corte.

Quanto à $4^{\text {a }}$, NÃO. O mandado de segurança merece indeferimento, eis que o ato impugnado tem inteiro amparo na Constituição - art. 144, I, II, III e IV - e não destoa da Lei Complementar $n^{\circ} 35$, de 14-3-1979 - art. 100 seu $\S 4^{\circ}$, cujas disposições devem ser interpretadas em harmonia com os citados textos da Lei Maior

ÉoPARECER

Porto Alegre, 23 de novembro de 1983.

Carlos Thompson Flores

\title{
El convenio relativo a la protección del niño y la cooperación en materia de adopción internacional de La Haya y la adopción internacional en Alemania*
}

\author{
Dr. Christoph Benicke \\ Universidad de Heidelberg, Alemania
}

\section{Introducción}

1. Importancia de la adopción internacional

Las adopciones internacionales han tomado hoy día una gran importancia real. En Alemania el período donde por primera vez se efectuaron un considerable numero de adopciones internacionales fue después de la segunda guerra mundial ${ }^{1}$. Alemania estaba destruida, muchos niños habían perdido sus padres en la guerra y otros padres no se veían en capacidad de criar a sus propios hijos, por la condición social o económica. Los padres adoptivos provenían de los países ganadores de la guerra, sobre todo de los Estados Unidos.

Estas adopciones tienen todavía una cierta actualidad cuando los niños adoptados vienen a Alemania para buscar sus raices biológicas ${ }^{2}$. Además son de gran importancia en cuanto al derecho sucesorio. Cuando un pariente de la familia biológica muere, se cuestiona si estos niños adoptados forman parte de los herederos legales ${ }^{3}$. Estos casos son relativamente frecuentes debido a que los padres 0 los tíos biológicos hoy son de una edad muy avanzada: Familias que en aquellos tiempos eran muy pobres, pueden haber hecho una gran fortuna, que en el momento de la sucesión debe ser repartida.

\footnotetext{
Este es la versión escrita y ampliada de una conferencia dada el 11 de abril de 1997 en la Universidad Federal de Rio Grande do Sul.

Literatura citada en forma abreviata: Benicke. Typenmehrheit im Adoptionsrecht und deutsches IPR, Frankfurt/ Main 1995; Hohnerlein. Internationale Adoption und Kindeswohl, Baden-Baden 1991; Jayme, Kulturelle Identität und Kindeswohl im internationalen Kindschaftsrecht, IPRax 1996, $237 \mathrm{ss}$.: Krause, Adoption, International Encyclopedia of Comparative Law, VI ch. 6; Lima Marques, Das Subsidiaritätsprinzip in der Neuordnung des internationalen Adoptionsrechts, Frankfurt/Main 1997; Marx, Perspektiven der internationalen Adoption, Frankfurt/Main 1993; Parra-Aranguren, Rapport explicatif de la convention du 29 mai 1993 sur la protection des enfants et la cooperation en matière d adoption internationale, ed. Conference de La Haye de droit international privé; Trillat/Nabinger, Adopción internacional y tráfico de niños. Mito y realidad, R.I.P.C. 1991 , p. 18 ss.

Abreviaciones de revistas: FamRZ: Zeitschrift fuer das gesamte Familienrecht; IPRax: Praxis des Internationalen Privat- und Verfahrensrecht; NDV: Nachrichtendienst des Deutschen Vereins fuer oeffentliche und private Fuersorge, RablZ: Rabels Zeits Magnus/Münzel, Adoptionen von Kindern aus Ubersee, StAZ 1977, p. 66 s.; Silvermann/Weitzmann, Nonrelative Adoption in the United States, en Hoksbergen, Adoption in worldwide perspective, Berwyn 1986, p. 3 .

Ver los casos comunicados en el informe del Servicio internacional social en Alemania, Adoptierte suchen ihre

Ver la decisión del Bundesgerichtshof (Corte federal de Alemania) 14.12.1988, IPRax 1990, p. 55.
} 